\title{
Quem é o profissional da informação? algumas reflexões
}

Who is the information professional: some reflections

\author{
Miriam Vieira da CUNHA \\ Centro de Ciência da Informação Universidade Federal de Santa Catarina, Florianópolis, Brasil, \\ vieiradacunha.miriam@gmail.com
}

\section{Resumen}

El sector de información es, por su propia naturaleza, un sector heterogéneo. La diversidad de ambientes donde se producen estas actividades, la diversidad de sus actores y la interpenetración de sus quehaceres hace difícil caracterizar las áreas profesionales y sus nombres. En este sentido, las fronteras entre las ocupaciones de este sector no son claras. Según Abbott (1988), las profesiones forman un sistema. En este sistema, comparten espacios bajo el poder que cada una ejerce. Los límites de cada jurisdicción están siempre en disputa. La historia de estas disputas determina, según Abbott, la historia de las profesiones. La dificultad de definir el campo de las profesiones de la información es el resultado de estas interacciones, y de la incertidumbre de las funciones que deben ejercer estos profesionales en una realidad donde la tecnología cambia muy rápidamente. EI término "profesional de la información" abarca un amplio elenco de actividades con diversos nombres. En este sentido la integración de estos profesionales conlleva conflictos en la ocupación del campo. Este trabajo intenta reflexionar sobre la realidad del profesional de la información y sobre las contradicciones y variaciones conceptuales y terminológicas entre los distintos significados de este concepto en la literatura brasileña y española de Ciencias de la Información publicada en los últimos diez años. Se fundamenta en la sociología de las profesiones, especialmente en Abbott (1988) y Dubar (2005). El análisis de contenido se fundamenta en la técnica de Bardin (2007) y estudia tres variables: el nombre del profesional de la información, la definición y las competencias del profesional.

Palabras clave: Profesiones. Profesionales de la Información. Brasil. España.

\section{Introdução}

Este trabalho tem como propósito refletir sobre os paradoxos e incongruências da expressão "profissionais da informação." Trata-se de uma primeira abordagem de uma pesquisa que pretende analisar e comparar o uso destes conceitos no Brasil e na Espanha, nos últimos 10 anos. Neste sentido, faz uma primeira aproximação ao assunto, tentando evidenciar as diver-

\begin{abstract}
The information sector is, by its nature, an heterogeneous sector. The diversity of the professional environments where these activities occur, the diversity of its actors and interpenetration of their duties make difficult to characterize the professional areas and their names. In this sense, the boundaries that separate the occupations of this sector are not clear. According Abbott (1988), all the professions form a system. In this system, the professions divide their spaces in accordance with the power of that each one. The history of these disputes determines the history of professions. The difficulty in define the field of the information professions is a consequence of these interactions, the uncertainty of roles that these professionals should play in a reality where technological change is very rapid. The term "information professional" covers a wide field of activities with various This paper aims to reflect on the reality of the information professional, evoking the contradictions between the different meanings of the words that describe these professionals from the literature of Information Science from Brazil and Spain. It is based in research on the sociology of professions, following mainly Abbott (1988) and Dubar (2005). The content analysis is based on Bardin's technique, and considers three variables: the names of the professions, their definitions and their competences.
\end{abstract}

Keywords: Profesions. Information professionals. Brazil. Spain.

gências e contradições dos diferentes significados deste termo na literatura de Ciência da Informação nos dois países.

O objetivo é tentar sistematizar as variações da nomenclatura da área para melhor identificar o "campo de atuação dos profissionais da informação". Além disso, esta pesquisa pretende dar uma contribuição para os estudos e discussões do Grupo de Trabalho 6 - Informação, Educa- 
ção e Trabalho, da ANCIB - Associação Brasileira de Pesquisa e Pós-graduação em Ciência da Informação.

O setor informacional é, por sua própria natureza, um setor heterogêneo. A diversidade dos ambientes profissionais onde estas atividades acontecem, a diversidade dos seus atores e a interpenetração relativa de suas funções tornam, atualmente, difícil a caracterização dos espaços profissionais e de suas respectivas denominações. Sob este aspecto, os limites que separam as ocupações deste setor não são claros. Na realidade, a evolução da sociedade da informação dá a impressão de uma justaposição de seus espaços, de seus atores e de suas funções (Cunha, 2003).

Segundo Abbott (1988), o conjunto das profissões forma um sistema. Neste sistema, as profissões dividem espaços mais ou menos legitimados de acordo com o poder que cada uma delas exerce. Abbott define este sistema como uma estrutura que relaciona as profissões entre elas de tal forma que o movimento de uma afeta as outras. A evolução deste sistema de interdependências depende dos ajustes que acontecem entre as profissões, conseqüência da forma com que os diversos grupos profissionais controlam seus conhecimentos e competências. Neste sentido, o controle de cada profissão é determinado pelo domínio das abstrações que geram a prática profissional.

As fronteiras de cada jurisdição profissional estão sempre em disputa. Para Abbott, é a história desta "arena de disputas" que determina a história das profissões. A habilidade das profissões em negociar e manter seus limites jurisdicionais e, desta forma, controlar o seu espaço de atuação resulta, em parte do prestígio de seu sistema de conhecimento. Neste sentido, quanto maior o poder de abstração teórica de uma profissão, mais sólida ela será no espaço social e no sistema profissional (Cunha, 2000).

A evolução das profissões é, assim, o resultado de suas inter-relações. Dessa forma, a força e o sucesso de uma profissão são legitimados por uma delimitação clara de seu campo de competência, pela definição de um espaço próprio de ação e por meio de sua interação com outras profissões.

A dificuldade de se delimitar o campo das profissões da informação é conseqüência destas interações profissionais que na área da informação são cada vez mais freqüentes, da incerteza dos papéis que estes profissionais devem desempenhar em uma realidade onde as mudanças tecnológicas são muito rápidas.
Com a crescente difusão das tecnologias informacionais e das habilidades necessárias para utilizá-las e desenvolvê-las, as linhas entre tecnologias de conteúdo e acesso tornam-se indistintas. Como resultado deste fenômeno, os limites entre as profissões ligadas à informação são cada vez mais tênues. Por esta razão, estudar o significado do termo profissionais da informação, em suas múltiplas acepções, significa tentar entender os ambientes onde se inserem estes profissionais e as mudanças do contexto que estamos vivenciando.

\section{Convergências e divergências}

O termo "profissional da informação" cobre um campo de atividades bastante extenso com apelações extremamente variadas, mais ou menos específicas, de acordo com os atores que participam destas atividades. Ele começou a ser utilizado nos anos 80 nos Estados Unidos para designar (Clausen, 1991):

todo bibliotecário, documentalista, cientista da informação, intermediário, etc., cujo trabalho:

- Fundamenta-se na teoria e na prática da criação, acesso, validação, organização, transmissão, pesquisa e difusão da informação;

- Concerne a gestão dos recursos de informação;

- Utiliza tecnologias específicas da Ciência da Informação ou da Gestão da Informação.

A definição de Clausen parece indicar e reforçar a incerteza e os paradoxos ligados à complexidade desta tarefa.

\section{De acordo com Sergean (1977, p. 7)}

a dificuldade de definir o campo de informação é conseqüência da própria natureza da informação. Este recurso difere dos outros porque não é o campo exclusivo de um grupo profissional, mas concerne todos os indivíduos. Por esta razão, as questões relativas aos limites deste campo podem ser somente definidas através de regras arbitrárias. O que concerne o especialista de informação em uma situação pode não lhe dizer respeito em outra situação (...) O trabalho informacional é um trabalho que todo o mundo realiza no sentido em que, em determinadas condições, um advogado, um economista e um médico exercem atividades de informação.

Para Debons (1981), o termo profissional da informação denota uma necessidade de convergência de profissões díspares. Mesmo se seu sentido é lato, ele sugere certa unidade na diversidade. Na realidade, se os profissionais da informação exercem sua profissão em diferentes espaços, é possível reagrupá-los a partir de um conjunto de idéias que the são comuns associadas a conceitos ligados ao fluxo de infor- 
mação: entrada, tratamento, saída e memorização.

Este é também o ponto de vista de Miranda (2004, p. 10) quando considera

a tarefa de definir o profissional da informação é complexa e até mesmo paradoxal, se considerarmos a ambigüidade com que o termo vem sendo utilizado nas diversas áreas de pesquisa, de ensino e de prestação de serviços à comunidade."

Maceviciuté (apud Marchiori, 2004, p. 130) classifica os profissionais da informação em quatro grandes grupos, conforme especificado a seguir:

1. Historicamente, pode-se considerar como especialistas da informação somente aqueles que estão trabalhando em sub-campos especializados no setor de informação, cujas atividades (e principal objetivo profissional) envolvem o processamento, armazenagem e utilização da informação. Neste particular, estão incluídos os bibliotecários, documentalistas, bibliógrafos, arquivistas, cientistas da informação, pessoal envolvido com jornalismo e editoração e, ainda, os envolvidos com o gerenciamento da informação;

2. o gerenciamento (ou gestão) da informação pode ser ainda considerado uma atividade nãoinformativa tradicional, isto é, quando emprega recursos de informação e processos relativos à comunicação e à tecnologia de informação em outras áreas, envolvendo conceitos da teoria da administração;

3. especialistas do setor de tecnologia da informação, cujas atividades exigem tanto uma indústria como serviços especializados, podem ser considerados profissionais da informação;

4.devido à integração progressiva de diferentes áreas de comunicação com a área da informação, são igualmente profissionais da informação os especialistas na área de publicidade, propaganda, marketing e relações públicas.

Para Guyot (2004), a área das profissões da informação pode ser considerada uma "interprofissão" ocupada por profissionais de documentação, comunicação e gestão. Se é possível pensar que alguma destas áreas irá dominar esta campo profissional, segundo Guyot, é difícil prever qual destes profissionais o fará.

$\mathrm{Na}$ realidade atual, segundo Mueller (2004, p. 23) existe uma grande complexidade nos serviços de informação, nos quais trabalham profissionais de várias áreas do conhecimento. Ainda segundo esta autora:

Certamente há um consenso de que certas características mínimas são comuns a todos os chamados profissionais da informação, o que permite o uso da designação em vários contextos, mas o entendimento parece depender de quem usa o termo e da audiência à qual se dirige.
Em um trabalho conjunto com Crivellari afirmamos (Cunha \& Crivellari, 2004, p. 46-47) que até pouco tempo, a noção de profissional da informação era ligada apenas a grupos tradicionais com atividades bem definidas como os bibliotecários, os documentalistas, os museólogos e os arquivistas. Entretanto, o desenvolvimento dessas profissões consideradas "clássicas" do setor não impediu que profissionais de outros campos de atividade bastante diversificados ocupassem este espaço, originando o que Abbott (1988) denomina de "invasão" de um campo profissional por outros grupos.

É possível verificar, através dos diferentes autores citados, a falta de consenso sobre quem são os profissionais da informação. Quase todos estão de acordo quando afirmam que o trabalho com informação não é exclusivo de uma área profissional, e com a idéia de uma crescente integração de profissionais de diferentes áreas do conhecimento no trabalho com informação, integração esta que muitas vezes causa conflitos pela ocupação deste espaço. Na verdade, um dos problemas evidentes deste campo de atividade é que ele se desenvolveu de tal forma que perdeu sua jurisdição preliminar, evidenciando uma disputa por uma nova jurisdição. De acordo com Abbott (1988), este campo não é dominado por nenhum grupo profissional, mas continua a ser extremamente permeável seguindo caminhos bastante diversificados.

Nossa análise se complica se observarmos a última edição da Classificação Brasileira de Ocupações - CBO (2002). Esta classificação emprega o termo profissionais da informação para nomear genericamente bibliotecários, documentalistas e analistas de informação.

Nesta última edição da CBO, organizada segundo a noção de "família ocupacional," ocorreu um desmembramento: enquanto os museólogos e os arquivistas continuaram integrando uma mesma família, os bibliotecários passaram a constituir a ocupação principal de uma "nova família" criada para abrigar as mudanças em curso. Assim, sob o nome de "profissionais da informação" encontramos hoje os bibliotecários, documentalistas e analistas da informação, exigindo-se para o exercício dessas três ocupações a formação universitária em Biblioteconomia (Cunha \& Crivellari, 2004).

Esta nova versão, além de separar as profissões "clássicas" da informação não resolve bem a relação dos bibliotecários com os museólogos e arquivistas - já que a gestão de documentos abrange tanto bibliotecas como arquivos e museus. 
Uma outra dificuldade com relação ao emprego do termo profissional da informação no Brasil é que ele vem sendo freqüentemente empregado na literatura da área como sinônimo de "bibliotecário". Esta confusão de terminologia é conseqüência no nosso entender (Cunha \& Crivellari, 2004, p. 49):

- da diversificação dos suportes informacionais;

- da mudança do foco de competência das organizações;

- de uma diversificação de locais e práticas;

- de um aumento e de uma diversificação de alianças entre profissionais de vários campos do conhecimento.

Muito se tem escrito, nos últimos 10 anos, em vários países, com destaque para o Brasil e a Espanha, sobre os perfis, os papéis, as funções, as habilidades e competências, os espaços de trabalho, a atuação dos profissionais da informação e a relação destes profissionais com as mudanças da sociedade da informação.

Estes estudos revelam diferentes abordagens e pontos de vista. Considerando estes diversos enfoques de análise, estes trabalhos podem ser agrupados em:

- pesquisas sobre os espaços de trabalho destes profissionais: Lopes-Hernández (2003); Tejada Artigas \& Moreiro (2003), Martínez Andaluz (2003), Torrejón (1999), Moreiro (1998) (Espanha); Baptista (2000), Tomaél \& Alvarenga (2000), Cunha (2000), Biancardi (2002), Ferreira (2003) e Cunha et al (2004) (Brasil);

- estudos que têm como base a sociedade da informação, a globalização e as tecnologias. Este é o caso dos trabalhos de Arruda (1998), Tarapanoff (1999); Espírito Santo (2006); Crivellari et al. (2007) (Brasil) e Cronin (1998) (Estados Unidos);

- pesquisas que partem das noções de competência e habilidade. Este é o caso das pesquisas de Espinas (2004), Tejada Artigas e Yunta (2003) (Espanha); Wormell (1999) (Dinamarca); e dos estudos brasileiros de Castro (2000), Garbelini (2002), Campello e Abreu (2004), Bufrem e Pereira (2004), Faria et al. (2005) e Cunha (2007);

- investigações sob a luz da formação profissional: Abbott (1998) (Estados Unidos); Roman e Pioli (1998); García Marco \& Lacruz (2000) (Espanha). No Brasil podemos citar: Cunha (1999), Marcondes (1999), Cunha (2000), Souza (2001), Silva e Cunha (2002) e Miranda et al. (2006);
- reflexões sobre a diversidade conceitual do termo "profissional da informação": Cubillo (1999) (Chile); e no Brasil, os estudos de Oddone (1998), Witter (1999), Targino (2001) e Januzzi e Loureiro (2005).

- pesquisas sobre as condições e transformações no trabalho (Mangue e Crivellari, 2006; Pena e Crivellari, 2007; Souza e Silva, 2007);

- reflexões sobre ética profissional (Rasche, 2005; Souza, 2005 e 2007).

Nestes diferentes trabalhos é possível verificar a diversificação da terminologia da área. Mesmo quando utilizado como um coletivo, os profissionais que fazem parte deste grupo variam muito, confirmando a falta de consenso explicitada pelos autores analisados. Entretanto, embora exista uma certa concordância de opiniões com relação aos profissionais considerados como "clássicos" (bibliotecários, museólogos e arquivistas), a Classificação Brasileira de Ocupações, conforme analisado acima, desmembrou este grupo, trazendo mais confusão à terminologia da área.

Lopez Yepez, em estudo de 2007, tenta dividir os profissionais da informação em quatro diferentes categorias:

- os especialistas em tecnologias da informação e comunicação;

- os especialistas em documentação empresarial;

- os consultores e formadores;

- os bibliotecários e documentalistas.

Com relação à construção de espaços informacionais, Walter e Baptista, em pesquisa de 2008, p. 9 identificam

[...] dez profissões [...] envolvidas na construção [deste espaço] [...] e poderiam se autodenominar arquitetos da informação: especialistas em construção, bibliotecários ou arquivistas, educadores, psicólogos, desenhistas e engenheiros de software e/ou comunicólogos, engenheiros de sistemas e artistas gráficos."

Barbosa (1998) vai na mesma linha de pensamento quando afirma que não existe uma definição universalmente aceita a respeito do que é um profissional da informação. Resgata a definição de Porat, a partir de seus estudos de 1980 sobre a economia da informação quando afirma que profissionais da informação são todos aqueles "eventualmente remunerados para criar conhecimento, comunicar idéias, processar informação."

Cronin (1998) aponta para uma transferência gradual de papéis do profissional da informação: 
do papel tradicional de "buscador de informação" para os papéis de "aconselhador" e "mediador de informação"

Em um artigo de 2000, chamamos a atenção para o surgimento de uma diversificação das nomenclaturas, a partir de:

- uma confluência de profissões antes separadas, como, por exemplo, o gestor do conhecimento, uma mescla de administrador, analista e bibliotecário;

- diferentes especializações por tipos de documento, como por exemplo, o administrador de web sites, e

- novas responsabilidades, como, por exemplo, o papel de mediador da informação (Cunha, 2000, p. 91).

\section{Algumas considerações finais}

Do que estamos falando, então, quando falamos do profissional da informação? De profissões distintas e, por conseguinte, de especializações distintas, de espaços de trabalho distintos? Estamos falando de novas parcerias e demarcações de espaços, como "diluições" dos diferentes espaços profissionais?

É possível verificar até este momento de nossa análise que o grupo de profissionais da informação reflete:

- fazeres não exclusivos de uma única área profissional ou fazeres de uma "interprofissão", para usar a expressão de Brigitte Guyot;

- com denominações variadas que representam: diferentes espaços de atuação, diferentes funções ou responsabilidades, diferentes tipos de documentos, e ainda, diferentes especialidades.

Este artigo procurou, ainda que com o olhar fragmentado - fazer uma primeira aproximação das contradições inerentes à nomenclatura dos profissionais que operam e vivem da informação - fazer conexões, criar pontes entre os diversos estudos neste universo específico. Mesmo com todas as conexões disponíveis, nosso olhar é fragmentado, é sempre imperfeito, é pessoal, é às vezes contraditório - traz nossa marca, nossa cultura, nossa vivência. Enfim, é um pensar provisório, refletido a partir do pensar dos diferentes autores que discutem este tema. Tentamos, neste sentido, trazer algumas observações sobre o assunto, tratando de construir algumas pontes, a partir das nossas leituras. Pretendemos aprofundar a reflexão sobre este assunto, por meio da análise de artigos publicados nos periódicos brasileiros e espanhóis da área, nos últimos 10 anos.

Vivemos num mundo onde as fronteiras profissionais desaparecem e se confundem, com novas parcerias e alianças que subvertem a demarcação e os espaços das diferentes ocupações. Esperamos que esta pesquisa traga resultados que permitam conhecer melhor a realidade e a complexidade das profissões da informação.

\section{Referencias}

Abbott, A. (1988). The system of professions. Chicago: The University of Chicago Press, 1988.

Abbott, C. M. (1998). Personal career development in converged services. // Librarian Career Development. ISSN 0968-0810. 6:3 (1998) 28-35.

Arruda, M. C. C. (1998). Reflexos do processo de globalização na capacitação profissional. // Informação \& Sociedade: Estudos. ISSN 1809-4783. 9:1 (1998) 1-10. http://www.ies.ufpb.br/ojs2/index.php/ies (2009-05-02).

Baptista, S. G. (2000). Profissional da informação: autônomo ou empresário, novas perspectivas de mercado de trabalho. // Perspectivas em Ciência da Informação. ISSN 1413-9936. 5:1 (Janeiro/Junho 2000) 91-98. http://www.scielo.br/scielo.php?script=sci_serial\&pid=14 13-9936\&lng=e\&nrm=iso (2009-04-25).

Barbosa, R. R. (1998). Perspectivas profissionais e educacionais em biblioteconomia e ciência da informação. // Ciência da Informação. ISSN 1518-8353. 27:1 (Janeiro/Abril 1998) 53-60. http://revista.ibict.br/index.php/ciinf (2009-04-30).

Bardin, L. (2004). L'analyse de contenu. Paris: PUF, 2004.

Biancardi, A. M. R.; Facini, B.; Rosemberg, D. S.; Ricardo, S. P. (2002). O cenário do mercado de trabalho em Biblioteconomia na percepção dos empresários capixabas. // Perspectivas em Ciência da Informação. ISSN 1413-9936. 7:2 (Julho/Dezembro 2002) 167-178. http://www.scielo.br/scielo.php?script=sci_serial\&pid=14 13-9936\&lng=e\&nrm=iso (2009-05-02).

Brasil. Ministério do Trabalho e Emprego (2002). Classificação Brasileira de Ocupações - CBO2002. http://www.mtecbo.gov.br/ (2007-07-07).

Bufrem, L. S.; Pereira, E. C. (2004). Os profissionais da informação e a gestão de competências. // Perspectivas em Ciência da Informação. ISSN 1413-9936. 9:2 (Julho/Dezembro 2004) 170-181. http://www.scielo.br/ scielo.php?script=sci_serial\&pid=1413-9936\&lng=e\&nrm =iso (2009-04-28).

Campello, B.; Abreu, V. L. F. G. (2005). Competência informacional e a formação do bibliotecário. // Perspectivas em Ciência da Informação. ISSN 1413-9936. 10:2 (Julho/Dezembro 2005) 178-193. http://www.scielo.br/ scielo.php?script=sci_serial\&pid=1413-9936\&lng=e\&nrm =iso (2009-04-29).

Castro, C. A. (2000). Profissional da informação: perfil e atitudes desejadas. // Informação \& Sociedade: Estudos. ISSN 1809-4783. 10:1 (2000) 1-13. http://www.ies. ufpb.br/ojs2/index.php/ies (2009-05-02).

Clausen, H. (1991). The future information professional: old wine in new bottles? Part Two. // Libri: International Journal of Libraries and Information Services. ISSN 0024-2667. 40:2 (December 1991) 265-277.

Crivellari, H. M. T.; et al. (2007). Olhares sobre o trabalho em organizações públicas e privadas na sociedade da 
informação. // Revista Educação e Tecnologia, 1 (2007) 1-6.

Cronin, B. (1998). Information professionals in the digital age. // The International Information and Library Review. ISSN 1057-2317. 30:1 (March 1998) 37-50.

Cubillo, J. (1999). El profesional sin nombre: reflexiones sobre una reflexión. Chile: CEPAL/CLADES Comunicado, 1999.

Cunha, M. V. (1999). A formação em Ciência da Informação na França, no Canadá e na Dinamarca. // Encontros Bibli: Revista Eletrônica de Biblioteconomia e Ciência da Informação. ISSN 1518-2924. 4:8 (1999) 20-27. http://www.periodicos.ufsc.br/index.php/eb (2009-01-05).

Cunha, M. V. (2000). A formação dos profissionais da Informação na França. // Valentim, Marta (org.). Profissionais da informação: formação, perfil e atuação profissional. São Paulo: Polis, 2000. 71-90.

Cunha, M. V. (2003). Reflexiones sobre la diseminación de informaciones. // Ciencias de La Información. ISSN 1606-4925. 34:1 (Abril 2003) 25-29.

Cunha, M. V. (2007). Bibliotecários e arquivistas: novos fazeres na sociedade do conhecimento. // Ponto de Acesso: Revista do Instituto de Ciência da Informação da UFBA. 1:1 (Junho 2007) 99-106. http://www.portalseer.ufba.br/index.php/revistaici (200905-02).

Cunha, M. V.; Crivellari, H. M. T. (2004). O mundo do trabalho na sociedade do conhecimento e os paradoxos das profissões da informação. // Valentim, Marta (org.). Atuação profissional na área de informação. São Paulo: Polis, 2004. 41-54.

Cunha, M. V.; Pereira, M. C.; Guimarães, C.; Silva, C. C. M. (2004). Bibliotecário formado pela Universidade Federal de Santa Catarina: perfil profissional. // Perspectivas em Ciência da Informação. 9:2 (Julho/Dezembro 2004) 182195. http://www.scielo.br/scielo.php?script=sci_arttext\& pid=S1413-99362007000100002\&lng=e\&nrm=iso.

Dubar, C. A socialização: construção das identidades sociais e profissionais.São Paulo: Martins Fontes, 2005.

Debons, A. et al (1981). The information professional: survey of and emerging field. New York: M. Dekker, 1981.

Espinás, E.O. (2004) Competencias profesionales y uso de la información en el lugar de trabajo. // El Profesional de la Información, 13:5 (sep/oct.2004). http://www.elprofesionaldelainformacion.com/ (2009-0415).

Espirito Santo, S. M. (2006). A mediação do profissional da informação nas florestas da sociedade da informação. // TransInformação. ISSN 0103-3786. 18:2 (Maio/Agosto 2006) 95-102. http://revistas.puc-campinas.edu.br/trans info/index.php (2009-04-20).

Faria, S.; Oliveira, V. F.; Forner, L.; D'Astuto, F. (2005). Competências do profissional da informação: uma reflexão a partir da Classificação Brasileira de Ocupações. // Ciência da Informação. ISSN 1518-8353. $34: 2$ (Maio/Agosto 2005) 26-33. http://revista.ibict.br/in dex.php/ciinf (2009-04-30)

Ferreira, M. M. (2003). O profissional da informação no mundo do trabalho e as relações de gênero. // Translnformação. ISSN 0103-3786. 15:2 (Maio/Agosto 2003) 189-201. http://revistas.puc-campinas.edu.br/transinfo/ index.php (2009-05-12).

Garbelini, M. F. (2002). El trabajo del documentalista y la gestión de la información de los medios de comunicación digitales: el caso de la prensa. // Scire: representación y organización del conocimiento. ISSN 1135-3716. 8:2 (Julio/Diciembre 2002) 153-158.

García Marco, F.; Lacruz, M.C.A. (2000). Educating the information profesional of the 21 st century: a ten-point proposal based on the Spanish context. Education for Information. 18 (2000) 141-153.

Guyot, B. (2004). Sciences de l'Information et activité professionnelle. // Hermès. 38 (Mai 2004) 1-9.

López Hernández , F. (2003) La "crisis de identidad" de los profesionales de la información. // El Profesional de la Información. 12:1 (Ene./feb. 2003). http://www.elprofe sionaldelainformacion.com/ (2009-05-02).

Lopéz Yepes, J. (2007) El nuevo profesional de la información, del conocimiento y de la comunicación. El bibliotecario universitario. // Anales de Documentación. 10:10 (2007), 263-279. http://revistas.um.es/index.php/ana lesdoc (2009-04-30).

Loureiro, M. F.; Jannuzzi, P. M. (2005). Profissional da informação: um conceito em construção. // TransInformação. ISSN 0103-3786. 17:2 (Maio/Agosto 2005) 123151 http://revistas.puc-campinas.edu.br/transinfo/index .php (2009-04-20).

Mangue, M. V.; Crivellari, H. M. T. (2006). Informatização e organização do trabalho em bibliotecas universitárias: estudo comparado entre Brasil, Moçambique e África do Sul. // Encontros Bibli: Revista Eletrônica de Biblioteconomia e Ciência da Informação, Florianópolis. N. Especial (2006) 147-163. http://www.periodicos.ufsc.br/in dex.php/eb (2009-01-05).

Marchiori, P. Z. (2004). Profissionais da Informação: multidimensionalidade, consiliência e a formação em Gestão da Informação. // Baptista, Sofia Galvão; Mueller, Suzana Pinheiro Machado (orgs.). Profissional da informação: o espaço de trabalho. Brasília: Thesaurus, 2004. 127-153.

Marcondes, C. H. (1999). Tecnologias da informação e impacto na formação do bibliotecário. // TransInformação. ISSN 0103-3786. 11:3 (1999). http://revistas.puccampinas.edu.br/transinfo/index.php (2009-04-15).

Martinez-Andaluz, J.A. (2003). Perspectivas profesionales y de empleo en las bibliotecas de las universidades públicas españolas. El Profesional de la Información, 12:1, (Ene./feb. 2003). http://www.elprofesionaldelainforma cion.com/ (2009-05-02).

Miranda, A. C. (2004). Introdução: duas abordagens no processo de definição do profissional da informação à guisa de apresentação. // Baptista, S.G.; Mueller, S. P. M. (orgs.). Profissional da informação: o espaço de trabalho. Brasília: Thesaurus, 2004. 15-19.

Miranda, A. C. C.; Solino, A. S. (2006). Educação continuada e mercado de trabalho: um estudo sobre os bibliotecários do Estado do Rio Grande do Norte. // Perspectivas em Ciência da Informação. ISSN 1413-9936. 11:3 (Setembro/Dezembro 2006) 383-397. http://www.scie lo.br/scielo.php?script=sci_serial\&pid=14139936\&lng=e\&nrm=iso (2009-05-13).

Moreiro, J. A. (1998) Mercado de trabajo y competências profesionales en Biblioteconomia, Documentación: técnicas aplicables a su investigación. // Informação \& Sociedade: Estudos, 8:1 (1998). http://www.ies.ufpb.br/ ojs2/index.php/ies (2009-05-05).

Mueller, S. P. M. (2004). Uma profissão em evolução: profissionais da informação sob a ótica de Abbott. // Baptista, Sofia Galvão; Mueller, Suzana Pinheiro Machado (orgs.). Profissional da informação: espaço de trabalho. Brasília: Thesaurus, 2004. 23-54.

Oddone, N. (1998). O profissional da informação e a mediação de processos cognitivos: a nova face de um antigo personagem. // Informação \& Sociedade: Estudos. 8:1 (1998) 1-11. http://www.ies.ufpb.br/ojs2/index. php/ies (2009-05-04)

Pena, A. S. ; Crivellari, H. M. T. (2007). Transformações políticas e mudanças no trabalho do profissional da in- 
formação: 1985 a 2005. // Revista Educação \& Tecnologia. (2007) 1-6.

Rasche, F. (2005). Questões éticas para bibliotecários. // Encontros Bibli. 19 (2005). http://www.periodicos. ufsc.br/index.php/eb (2009-10-05).

Roman, E.; Pioli, A. (1998). El profesional de la información y su capacitación permanente en un entorno signado por los cambios. // Scire: representación y organización del conocimiento. 4:2 (Julio/Diciembre 1998) 23-34.

Sergean, R. (1977). Librarianship and information work: job characteristics and staffing needs. Boston Spa: The British Library Board, 1977.

Silva, E. L.; Cunha, M. V. (2002). Los profesionales de la información y los dilemas educacionales del mundo globalizado. // Scire: representación y organización del conocimiento. ISSN 1135-3716. 8:2 (Julio/Diciembre 2002) 23-32.

Souza, F. C. (2005). Conduta profissional, discurso ético e etica do discurso na Biblioteconomia. // Informação \& Sociedade: Estudos. 15:1 (2005) 1-15. http://www.ies. ufpb.br/ojs2/index.php/ies (2009-04-28).

Souza, F. C. (2001). A Escola de Biblioteconomia e a ancoragem da profissão do bibliotecário. // Informação \& Sociedade: Estudos. ISSN 1809-4783. 11:2 (2001) 1-12. http://www.ies.ufpb.br/ojs2/index.php/ies (2009-04-28).

Souza, F. C. (2007). Ética bibliotecária no contexto atual. Perspectivas em Ciência da Informação, 12, (2007), 136-147. http://www.scielo.br/scielo.php?script=sci_serial\&pid=14 13-9936\&lng=e\&nrm=iso (2009-03-28).

Tarapanoff, K. (1999). O profissional da informação e a sociedade do conhecimento: desafios e oportunidades. // TransInformação. ISSN 0103-3786. 11:1 (Janeiro/Abril 1999). http://revistas.puc-campinas.edu.br/transinfo/ind ex.php (2009-04-10).

Targino, M. G. (2001). Quem é o profissional da informação. // TransInformação. ISSN 0103-3786. 12:2 (2001). http://revistas. puc-campinas.edu.br/transinfo/index.php (2009-05-02)

Tejada Artigas, C.; Yunta, L. R., (2003). Sistematizaciones de competencias de los profesionales de la información. Valoración de la relación de Decidoc por los asociados de Sedic. // El Profesional de la Información. 12:1, (ene/feb.2003). http://www.elprofesionaldelainformacion. $\mathrm{com} /$ (2009-05-02)

Tejada Artigas, C.; Moreiro, J. A. (2003). Mercado de trabajo en Biblioteconomía y Documentación. Estudios sobre la inserción laboral de los titulados universitários.// El Profesional de la Información, v.12, n.1, ene/feb.2003. http://www.elprofesionaldelainformacion.com/ (2009-0501).

Tomaél, M. I.; Alvarenga, G. M. (2000). Profissional da informação: seu espaço e atuação em empresas industriais. // Perspectivas em Ciência da Informação. ISSN 1413-9936. 5:1 (Janeiro/Junho 2000) 81-90. http://www.scielo.br/scielo.php?script=sci_serial\&pid=14 13-9936\&lng=e\&nrm=iso (2009-05-01).

Torrejón, M. (1999) Los nuevos yacimientos de empleo para los profesionales de la información. // Scire. Zaragoza. 5:1 (ene./jun.1999) 77-90.

Walter, M. T. M. T.; Baptista, S.G. (2008). Formação profissional do bibliotecário. // Encontros Bibli: Revista Eletrônica de Biblioteconomia e Ciência da Informação. 13:25, (1 sem.2008) 84-103. http://www.periodicos.ufsc.br/in dex.php/eb (2009-12-05).

Witter, G. P. (1999). Profissional da informação: caracterização e busca de instrumentos para avaliação. // TransInformação. ISSN 0103-3786. 11:1 (Janeiro/Abril
1999). http://revistas.puc-campinas.edu.br/transinfo/ind ex.php (2009-05-02).

Wormell, I. (1999). Habilidades de gerenciamento e de empreendimento na profissão de bibliotecário e cientista da informação. // Informação \& Informação. ISSN 19818920. 4:1 (Janeiro/Junho 1999) 7-16. http://revistas.puccampinas.edu.br/transinfo/index.php (2009-04-30). 